\title{
The role of HIV-I DNA levels in HIV-related lymphoma patients treated with autologous stem cell transplantation (ASCT)
}

Maria Teresa Bortolin, Stefania Zanussi, Rosamaria Tedeschi, Renato Talamini', Chiara Pratesi, Cecilia Simonelli², Giancarlo Basaglia, Paolo De Paoli ${ }^{3}$

S.O.C. di Microbiologia, Immunologia e Virologia,

I S.O.C. Epidemiologia e Biostatistica,

2 Oncologia Medica A,

3 Direzione Scientifica, Centro di Riferimento Oncologico, IRCCS, Aviano (PN)

Key words: HIV-I DNA, autologous stem cell transplantation (ASCT), overall survival (OS)

Valutazione dei livelli di HIV-I DNA in pazienti con linfoma riceventi trapianto autologo di cellule staminali (ASCT)

SUMMARY

Objective. Aim of our study was to evaluate the kinetics of HIV-I DNA levels (HIV DNA) and its clinical role in HIV-related lymphoma patients undergoing autologous stem cell transplantation (ASCT).

Materials and methods. HIV DNA was measured by real-time PCR in the peripheral blood mononuclear cells (PBMCs) of 22 patients, 16 with non-Hodgkin's lymphoma and 6 with Hodgkin's disease.

Results: Baseline HIV DNA levels were associated with HIV-I RNA levels (HIV RNA) $(r=0.56, p=0.02)$, but not with CD4 counts ( $r=$ $0.10, p=0.68$ ). The viremia was undetectable for all the follow-up time post-ASCT, while HIV DNA could be evaluated in a high percentage of patients before ASCT and during the entire follow-up (median, 89.5\%). At 3 months and at I year from transplantation, the median HIV DNA levels were II 3 copies/ I $0^{6}$ PBMCs (baseline vs. 3 months, $p>0.05$ ) and 66 copies/ I $0^{6}$ PBMCs (baseline vs. I year, $p>0.05$ ), respectively. Moreover, baseline HIV DNA levels were significantly different between alive and deceased patients $(p=0.03)$, and the overall survival (OS) analysis showed that patients with higher HIV DNA levels at baseline had an increased and nearly significant risk of dying if compared to patients with lower levels $(\mathrm{HR}, 8.33,95 \% \mathrm{Cl}, 0.99-70.06, p=0.05)$.

Conclusions: Our study demonstrated the association between increased HIV DNA levels at baseline and overall survival after ASCT, in one of the largest cohorts of HIV-lymphoma patients, treated with salvage therapy.

\section{INTRODUZIONE}

Il corretto monitoraggio del paziente HIV-infetto si basa essenzialmente sulla valutazione di alcuni parametri immunologici, come il numero di linfociti T CD4+, e sul dosaggio della viremia plasmatica (HIV RNA). Il controllo della viremia ed il conseguente recupero del danno immunlogico dovuto alla terapia antiretrovirale ad alta attività (HAART), rende necessario l'utilizzo di ulteriori marcatori di laboratorio sia immunologici che virologici.

La quantificazione del DNA provirale di HIV (HIV DNA) rappresenta uno dei parametri virologici più importanti per monitorare l'infezione da HIV in pazienti sottoposti ad HAART. Infatti, diversi e recenti studi hanno dimostrato l'utilità clinica del dosaggio dei livelli di HIV DNA nei linfomonociti di sangue periferico (PBMCs), quale marcatore precoce di ripresa della replicazione virale, in caso di fallimento terapeutico o durante le interruzioni del trattamento, e come possibile marcatore di progressione dell'infezione di HIV, indipendentemente dalla viremia ed il numero dei linfociti T CD4+ (12, 16, 17, 19).

Il rischio di sviluppare linfomi non-Hodgkin (NHL) e Hodgkin (HD) è significativamente più elevato nei pazienti HIV-positivi rispetto ai soggetti HIV-negativi. I linfomi HIV-correlati, inoltre, presentano delle caratteristiche cliniche particolarmente aggressive e solitamente hanno una prognosi peggiore, rispetto alla popolazione generale. L'HAART ha migliorato la sopravvivenza dei pazienti con linfomi HIV-correlati, tuttavia alla ricaduta questi mantengono una prognosi molto infausta. Nel nostro Istituto i pazienti con NHL o HD, refrattario o in ricaduta dopo chemioterapia (CT) convenzionale, vengono trattati con chemioterapia ad alte dosi (HDC) seguita da trapianto autologo di cellule staminali (ASCT).

Dal 2003 ad oggi alcuni ricercatori hanno dimostrato l'efficacia e la fattibilità di questa terapia di salvataggio in termini di recupero immunologico e di controllo della viremia $(2,4,10$,
$13,14,15,18)$, tuttavia alcuni quesiti rimangono ancora irrisolti, tra i quali lo studio dell'entità e della cinetica del "reservoir” virale (HIV DNA) durante il trapianto.

Lo scopo del nostro lavoro è stato valutare la cinetica della quantità di HIV DNA ed il suo significato clinico in pazienti con linfoma, ricaduti o refrattari alla chemioterapia di prima linea, trattati con HAART e sottoposti a HDC e ASCT (5).

\section{MATERIALI E METODI}

\section{Pazienti}

Nel nostro Istituto da maggio 2001 a giugno 2006, 46 pazienti HIV positivi con linfoma, ricaduti o refrattari alle chemioterapie convenzionale, sono stati arruolati per la terapia di salvataggio (HDC seguita da ASCT). Abbiamo selezionato solo i 22 pazienti (2 donne e 20 uomini) per i quali il trapianto autologo è stato possibile. Sei pazienti erano affetti da HD e 16 da NHL alto grado. L'età mediana all'arruolamento era di 42 anni (interquartile range, IQ, 39-48 anni). I pazienti sono stati seguiti per un anno dall'ASCT e durante questo periodo sono stati monitorati all'arruolamento (considerato prima della CT di debulking o di seconda linea, atta ad eliminare o ridurre l'entità del linfoma), alla leucaferesi (prima cioè della raccolta delle cellule CD34+), prima dell'HDC (o terapia di condizionamento), a due settimane dall'ASCT (periodo aplastico) e a 1, 3 fino a 12 mesi dall'ASCT. Tutti i pazienti erano sottoposti ad HAART prima e dopo il trapianto, ma per 10 pazienti intorno all'HDC è stato necessario interrompere la terapia antiretrovirale, causa tossicità epatica e/o gastroenterica. Per ciascun paziente e tempo il plasma è stato separato dal sangue intero, raccolto in EDTA, mediante semplice centrifugazione, ed i PBMCs sono stati separati mediante centrifugazione su gradiente di Ficoll-Hypaque. I pellet ciascuno con circa $5 \times 10^{6}$ PBMCs sono stati congelati a $-80^{\circ} \mathrm{C}$ prima delle analisi. Il DNA genomico è stato estratto mediante lisi cellulare e fenolo/cloroformio.

\section{Corresponding author: Maria Teresa Bortolin}

S.O.C. di Microbiologia, Immunologia e Virologia - Centro di Riferimento Oncologico, IRCCS

Via F. Gallini, 2 - 3308I Aviano (PN) - Tel: +39 (0)434 65942I - Fax: +39 (0)434 659402

E-mail: mtbortolin@cro.it 


\section{Dosaggio della proviremia}

La quantificazione dei livelli di HIV DNA nei PBMCs è stata eseguita mediante real-time PCR (ABI PRISM 7900HTApplied Biosystems), apportando alcune modifiche ad un metodo già pubblicato (20). In sintesi, questo sistema prevede l'amplificazione di un frammento di $121 \mathrm{pb}$ della sequenza genica long terminal repeat (LTR) del genoma di HIV-1, la cui amplificazione consente di rilevare sia il DNA di HIV-1 integrato che le forme lineari o circolari del DNA di HIV-1 non integrato nella cellula ospite. Le sequenze dei primer a monte e a valle sono: 5'-GCCTCAATAAAGCTTGCCTTGA-3' e 5'-GGCGCCACTGCTAGAGATTTT-3'. La sonda fluorigenica tipo TaqMan interna al frammento da amplificare ha sequenza: 5'-FAM-AAGTAGTGTGTGCCCGTCTGTTRTKTGACT-TAMRA-3'. In ciascun pozzetto della piastra da 96 pozzetti sono stati aggiunti $5 \mu \mathrm{l}$ di campione e $20 \mu \mathrm{l}$ di miscela di PCR, contenente $12.5 \mu$ l di Universal Master Mix 2X (Applied Biosystems), 1,5 mM di magnesio cloruro, 7.5 pmoli dei primer e sonda rispettivamente. La mix contiene anche l'enzima uracil N-glicosilasi (UNG) che previene l'amplificazione di prodotti di PCR, eventualmente amplificati nelle precedenti sedute di PCR. I cicli di amplificazione sono stati: $50^{\circ} \mathrm{C}$ per 2 minuti, $95^{\circ} \mathrm{C}$ per 10 minuti, e 50 cicli ciascuno a $95^{\circ} \mathrm{C}$ per 15 secondi e $60^{\circ} \mathrm{C}$ per 1 minuto.

Lo standard utilizzato è costituito da 4 quantità a titolo noto di DNA di HIV-1 (5000, 500, 50 e 5 copie HIV DNA/reazione), derivante dalla linea cellulare ACH-2, le cui cellule contengono ciascuna 1 copia del genoma di HIV-1 integrata nel genoma. Ciascun punto della curva standard, del campione e dei controlli positivo e negativo sono stati dosati in triplicato. Inoltre, nel terzo pozzetto di ciascun campione è stata aggiunta una quantità di HIV DNA a titolo noto (500 copie HIV DNA/reazione), come controllo di inibizione per valutare la percentuale di inibizione su cui eventualmente normalizzare il dosaggio. La sensibilità della PCR è pari a 2.5 copie/ $10^{6}$ PBMCs. Per esprimere la quantità di HIV DNA per milione di PBMCs, il numero di cellule è stato calcolato mediante una real time PCR per il gene della $\beta$-globina (3). Le analisi sono state ripetute quando il coefficiente di variazione era risultato superiore al $20 \%$ e $10 \%$ per l’HIV DNA e la $\beta$-globina, rispettivamente.

\section{Dosaggio della viremia}

Il dosaggio dei livelli di HIV RNA nel plasma è stato eseguito mediante un kit commerciale che si basa sulla metodica del branched-DNA (b-DNA, Chiron). La sensibilità del metodo è pari a 50 copie di HIV RNA/mL con un valore massimo rilevabile pari a 500000 copie HIV RNA/mL.

\section{Caratterizzazione fenotipica}

L'assetto immunologico dei pazienti è stato valutato mediante tipizzazione delle sottopopolazioni linfocitarie CD4+, CD8+, CD4+CD45RA+CD62L+ (naïve) e CD4+CD45RO+ (memory) mediante citofluorimetria. La metodica prevede l'aggiunta di una combinazione di anticorpi monoclonali coniugati a fluorocromi ad una piccola aliquota di sangue periferico in EDTA. Dopo incubazione, le emazie vengono lisate e le cellule vengono fissate con una preparazione commerciale (Immunoprep Coulter) e la fluorescenza emessa viene analizzata mediante il citofluorimetro a flusso EPICS XL MCL (Coulter, Milano, Italia).

\section{Analisi statistica}

Le correlazioni tra il numero dei linfociti T CD4+, i livelli di HIV RNA e HIV DNA all'arruolamento è stata valutata mediante la correlazione di Spearman $(r)$. Per valutare le differenze dei valori medi dei vari parametri immunologici e virologici durante il follow-up tra gruppi indipendenti è stato utilizzato il test non parametrico di Wilcoxon. Mentre per i confronti dei valori medi dei parametri HIV-DNA e linfociti T CD4+ all'interno della stessa popolazione di pazienti è stato utilizzato il test di Student per dati appaiati (Armitage and Berry, 1987). Inoltre, è stata valutata l'influenza dei para- metri immunologici/virologici e di alcuni parametri clinici sulla sopravvivenza globale e libera da malattia, con il calcolo dei rischi proporzionali (Hazard Ratio, HR) e dei corrispondenti intervalli di confidenza (CI) al 95\% di Cox (1972). Il rischio (HR) per le variabili continue è stato calcolato dicotomizzando le variabili sopra e sotto la mediana. Le curve di sopravvivenza globale per HIV-RNA, linfociti TCD4+ e HIV-DNA sono state disegnate con il metodo di KaplanMeier (1958), e le differenze tra i sottogruppi delle variabili sono state valute con test di log-rank. I risultati sono stati considerati statisticamente significativi per valori di $\mathrm{p} \leq 0.05$ (test a due code). Tutte le analisi sono state eseguite con il programma SAS System software release 8.2 (SAS Institute).

\section{RISULTATI}

Le caratteristiche di base dei pazienti all'arruolamento sono riportate in Tabella 1. Sette pazienti sono positivi anche per HCV. La conta mediana dei linfociti T CD4+ è di circa 200 cell/mL. Grazie all'HAART la viremia è sotto controllo con solo il 31.6\% di positività e mediana al di sotto del limite di rilevazione. Ben il 94.7\% dei pazienti risulta invece essere positivo per HIV DNA con mediana di 113 copie/ $10^{6}$ PBMCs. All'arruolamento i livelli basali di HIV DNA sono correlati a quelli di HIV RNA $(r=0.56, p=0.02)$, mentre non viene rilevata alcuna correlazione tra i livelli basali di HIV DNA ed il numero di linfociti T CD4+, ne' tra i livelli basali di HIV RNA e i linfociti T CD4+ $(r=-0.10, p=0.68$ e $r=-$ $0.17, p=0.49$, rispettivamente). Anche le correlazioni tra HIV DNA e le sottopopolazioni di linfociti T CD4+ memoria $\left(\mathrm{CD} 4^{+} \mathrm{CD} 45 \mathrm{R} 0^{+}\right)$o naïve $\left(\mathrm{CD} 4^{+} \mathrm{CD} 45 \mathrm{RA}^{+} \mathrm{CD}^{+} \mathrm{L}^{+}\right)$non sono statisticamente significative $(r=-0.14, p=0.59$ e $r=$ $0.07, p=0.78$, rispettivamente). La viremia, comunque, rimane sotto controllo per tutto il follow-up, eccetto per 8 pazienti per i quali s'è resa necessaria un'interruzione dell'HAART, intorno il primo mese dopo il trapianto, e nei quali la reintroduzione della stessa terapia antiretrovirale riporta i valori di HIV RNA al di sotto del limite di rilevazione. I livelli di HIV DNA sono comunque presenti in elevata percentuale prima del trapianto e durante l'intero follow-up (mediana, 89.5\%, IQR, 82.6-92.4).

In Figura I a è illustrata la cinetica del recupero dei linfociti T CD4+: alla raccolta delle cellule CD34+, i linfociti T CD4+ si espandono significativamente, il nadir è raggiunto a 15 giorni dall'ASCT e ad un anno dal trapianto i livelli raggiungono quelli del basale. In Figura I b è illustrata la dinamica dei livelli di HIV DNA: la proviremia è quasi sempre presente e, nonostante il calo significativo prima della raccolta delle cellule CD34+, ritorna subito a livelli sovrapponibili al basale. Lo studio del follow-up di questi pazienti copre un periodo mediano di 31.0 mesi (IQ, 11.0-52.0 mesi). Quattordici pazienti sono vivi, 13 in remissione completa e 1 in recidiva con tempo mediano di 47.6 mesi (IQ, 34.2-66.2 mesi), mentre sono stati osservati $8 / 22(36.4 \%)$ decessi in un tempo mediano di 8.4 mesi (IQ range, 6.6-11.0 mesi). Stratificando per pazienti vivi e deceduti, il recupero dei linfociti T CD4+ non è diverso per i due gruppi (Figura II a), mentre per quel che riguarda il reservoir virale, i pazienti che decedono entro un anno dal trapianto presentano livelli basali di HIV DNA significativamente più alti, rispetto ai pazienti che sopravvivono (mediana 184 copie HIV DNA/10 ${ }^{6}$ PBMCs contro 66 copie HIV DNA $/ 10^{6}$ PBMCs, $\mathrm{p}=0.03$ ), e questa differenza, anche se non più statisticamente significativa, si mantiene tra i due gruppi per tutto il follow-up (a 3 mesi dal trapianto mediana 165 copie HIV DNA/106 PBMCs contro 76 copie HIV DNA $/ 10^{6}$ PBMCs, p>0.05, Figura II b). L'analisi uni variata, mediante la regressione logistica, sulla sopravvivenza globale e libera da linfoma per alcuni parametri clinicodemografici, immunologici e virologici mette in evidenza che solo i valori basali di HIV DNA giocano un ruolo nel predire il rischio di morte dei pazienti dopo trapianto. Infatti, si evince che i pazienti con livelli superiori o uguali alla mediana all'arruolamento hanno un rischio di circa 8 volte superio- 
re di morire, rispetto ai pazienti con livelli inferiori alla mediana: HR (95\% IC) 8.33 (0.99-70.06); $\chi^{2}=3.81, p=0.05$ ). La sopravvivenza alla diagnosi, valutata secondo il metodo di Kaplan-Meier, conferma questo risultato (Figura III): i pazienti con livelli di HIV DNA superiori o uguali alla mediana hanno una probabilità di sopravvivenza ad un anno dall'ASCT del $25 \%$ contro il $100 \%$ per i pazienti con livelli sotto la mediana $\left(\chi^{2}=5.37 ; \mathrm{p}=0.02\right)$.

\section{DISCUSSIONE}

Il DNA di HIV-1 nei PBMCs rappresenta un parametro virologico di notevole importanza per valutare l'andamento dell'infezione e per monitorare la progressione della malattia, soprattutto in pazienti trattati con HAART (11). L'obiettivo del nostro studio è stato quello di analizzare i livelli di HIV DNA e valutare la loro importanza come marcatore molecolare prognostico in un gruppo di pazienti HIV-positivi affetti da linfoma, ricaduti o refrattari alla CT convenzionale e sottoposti ad HDC e ASCT.

La presenza di una correlazione, se pur non molto marcata, tra i livelli basali di HIV RNA e HIV DNA potrebbe essere dovuta all'incompleta efficacia dell'HAART in alcuni pazienti prima del trapianto. La mancanza di correlazione, tra il numero dei linfociti T CD4+ e i livelli di HIV DNA all'arruolamento, potrebbe, invece, dipendere dal severo stato di immunodepressione di questi pazienti prima del trapianto e dal breve lasso di tempo intercorso dalla fine della chemioterapia di prima linea.

Nonostante il recupero dei linfociti T CD4+ ed il controllo della viremia plasmatica ad un anno dal trapianto, i risultati ottenuti confermano che l'HIV DNA, rilevabile in quasi tutti
Tabella I. Caratteristiche dei 22 pazienti HIV positivi all'arruolamento CARATTERISTICHE N (\%)

SESSO

\begin{tabular}{|c|c|}
\hline Maschi & $20(90.9)$ \\
\hline Femmine & $2(9.1)$ \\
\hline \multicolumn{2}{|l|}{ ETA் } \\
\hline Mediana (IQ range), anni & $42(39-48)$ \\
\hline \multicolumn{2}{|l|}{ ISTOLOGIA DEL LINFOMA } \\
\hline $\mathrm{NHL}$ alto grado & $16(72.7)$ \\
\hline HD & $6(27.3)$ \\
\hline \multicolumn{2}{|l|}{ ETȦ ALL'INFEZIONE) } \\
\hline Mediana (IQ range), anni & $34(26-40)$ \\
\hline \multicolumn{2}{|c|}{ TEMPO SIEROCONVERSIONE-ARRUOLAMENTO } \\
\hline Mediana (IQ range), anni & $6(3-16)$ \\
\hline SIEROLOGIA HCV & $7(3 \mid .8)$ \\
\hline \multicolumn{2}{|l|}{ SUBSET LINFOCITARIO } \\
\hline CD4+ (cellule/ $\mu \mathrm{L})$ Mediana (IQ range) & $201(109-280)$ \\
\hline CD4+ (\%) & $15.0(11.0-22.0)$ \\
\hline CD8+ (cellule $/ \mu \mathrm{L})$ Mediana (IQ range) & $678(490-994)$ \\
\hline CD8+ (\%) & $58.0(46.0-70.0)$ \\
\hline CD4+CD45RO+ (cellule $/ \mu \mathrm{L})$ Mediana (IQ range & $122(83-170)$ \\
\hline CD4+CD45RO+ (\%) & $71.0(67.0-83.0$ \\
\hline 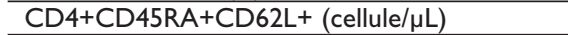 & $38(8-56)$ \\
\hline CD4+CD45RA+CD62L+ (\%) & $19.6(7.0-33.0)$ \\
\hline Rapporto CD4+ : CD8+ Mediana (IQ range) & $0.26(0.24-0.3 \mathrm{I})$ \\
\hline \multicolumn{2}{|l|}{ HIV RNA } \\
\hline Mediana (IQ range) copie/mL & $49(49-220)$ \\
\hline $\mathrm{N}$ positivi (\%) & $6(31.6)$ \\
\hline \multicolumn{2}{|l|}{ HIV DNA } \\
\hline Mediana (IQ range) copie//06 PBMCs & $113(53-165)$ \\
\hline $\mathrm{N}$ positivi (\%) & $18(94.7)$ \\
\hline
\end{tabular}

(a)

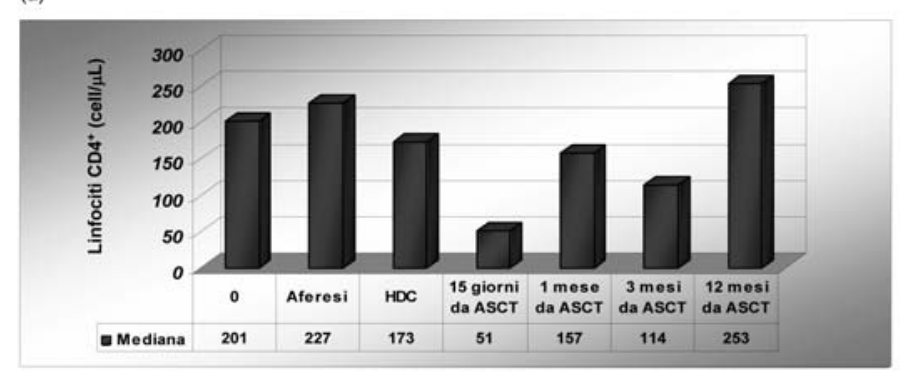

(b)
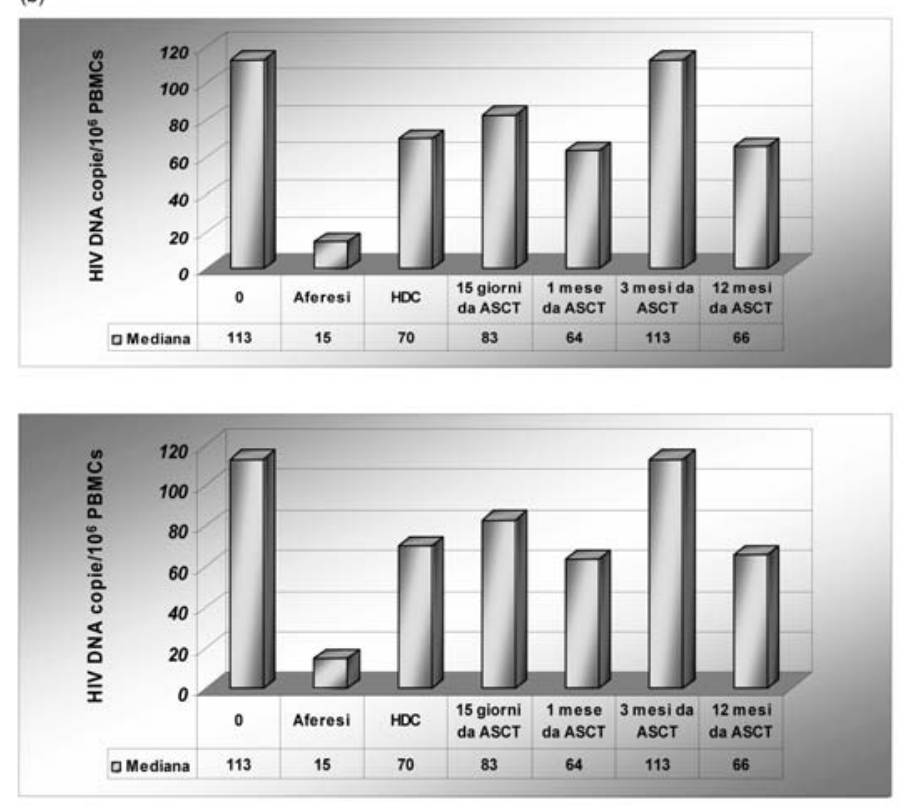

Figura I. Cinetica del recupero dei linfociti T CD4+ (a) e dei livelli di HIV DNA (b). i pazienti all'arruolamento $(\mathrm{T}=0)$, permane anche dopo trapianto con percentuali e livelli sovrapponibili al T0, in accordo con gli studi che dimostrano la presenza del "reservoir" virale anche in pazienti trattati con HAART $(8,9)$. Il calo significativo che si verifica prima della raccolta delle cellule CD34+ molto probabilmente è dovuto all'aumento delle cellule staminali a livello periferico ad opera del fattore stimolante i granulociti (G-CSF), utilizzato per la mobilizzazione.

Inoltre, altri studi hanno suggerito l'importante ruolo biologico dell'HIV DNA nella patogenesi della malattia da HIV, dimostrando che nei pazienti sieroconvertiti i livelli di HIV DNA erano il più importante fattore predittivo di progressione ad AIDS, indipendentemente dal numero dei linfociti CD4 e dalla viremia $(1,16)$. Successivamente si è dimostrato che i livelli di HIV DNA all'arruolamento sono associati alla sopravvivenza globale nei pazienti che ricevono terapia antiretrovirale (19). Nonostante l'esiguo numero di pazienti da noi analizzati, che tuttavia rappresenta una delle più ampie casistiche di pazienti sottoposti a trapianto autologo, il nostro studio ha dimostrato un'associazione tra alti livelli di HIV DNA all'arruolamento e la riduzione del tempo di sopravvivenza, indipendentemente dalla conta dei CD4 e dalla viremia. Infatti, i pazienti con livelli di HIV DNA al T0 $\geq 113$ copie $/ 10^{6}$ PBMCs avevano un rischio di circa 8 volte superiore di morire, rispetto ai soggetti con livelli <113 copies $/ 10^{6}$ PBMCs. La mancanza di associazione tra altri fattori, sia clinicodemografici che immuno-virologici, e la sopravvivenza, sia globale che libera da malattia, potrebbe dipendere molto probabil- 
mente dalla severa immunosoppressione e l'avanzato stadio di linfoma dei pazienti, prima della terapia di salvataggio. Inoltre, è interessante notare che i pazienti con un migliore decorso clinico dopo trapianto hanno mantenuto bassi livelli di HIV DNA durante tutto il follow-up. Non è ancora chiaro come nelle prime fasi dell'infezione primaria di HIV il "pool” di cellule HIV-infette si formi e si stabilizzi. Tuttavia, sembra che la differenza dei livelli di HIV DNA dipenda soprattutto da differenze genetiche tra i pazienti (7), e potrebbe essere influenzata da quando si inizia il trattamento con HAART (6).

Il nostro studio dimostra quindi un'associazione significativa tra sopravvivenza e quantità totale del reservoir periferico di HIV, che molto probabilmente si stabilisce nelle fasi più precoci dell'infezione (9). Questo risultato in questo particolare gruppo di pazienti potrebbe avere importanti implicazioni cliniche e stimolare altri ricercatori a valutare i livelli di HIV DNA, insieme ad altri parametri clinici e virologici, quale marcatore specifico di trapianto in coorti più ampie di pazienti HIVpositivi con linfoma. (a)

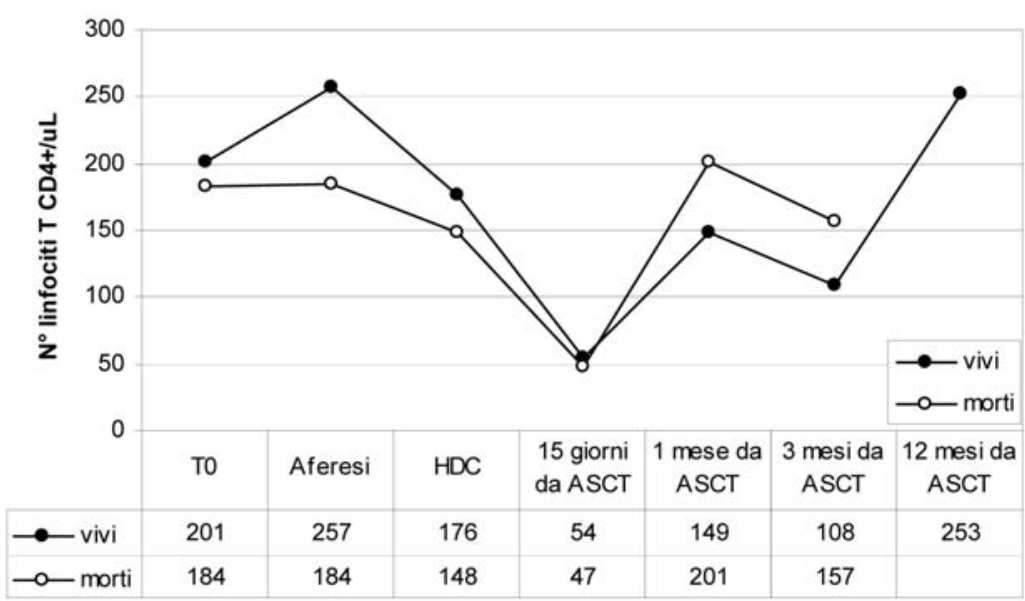

(b)

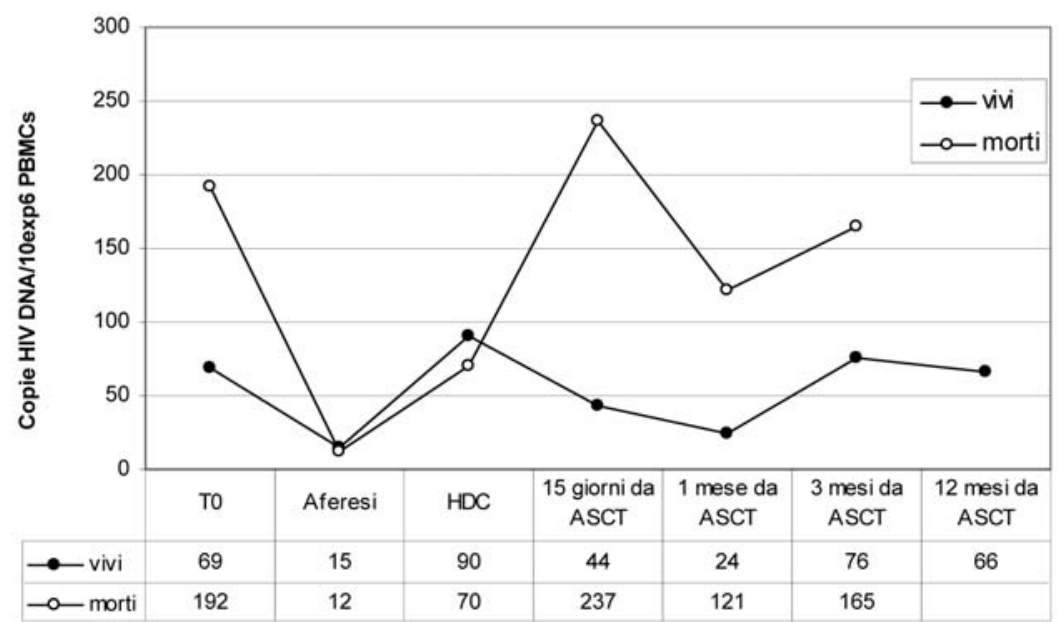

Figura II. Cinetiche del recupero dei linfociti T CD4+ (a) e dell'HIV DNA (b), stratificate per pazienti vivi e morti.

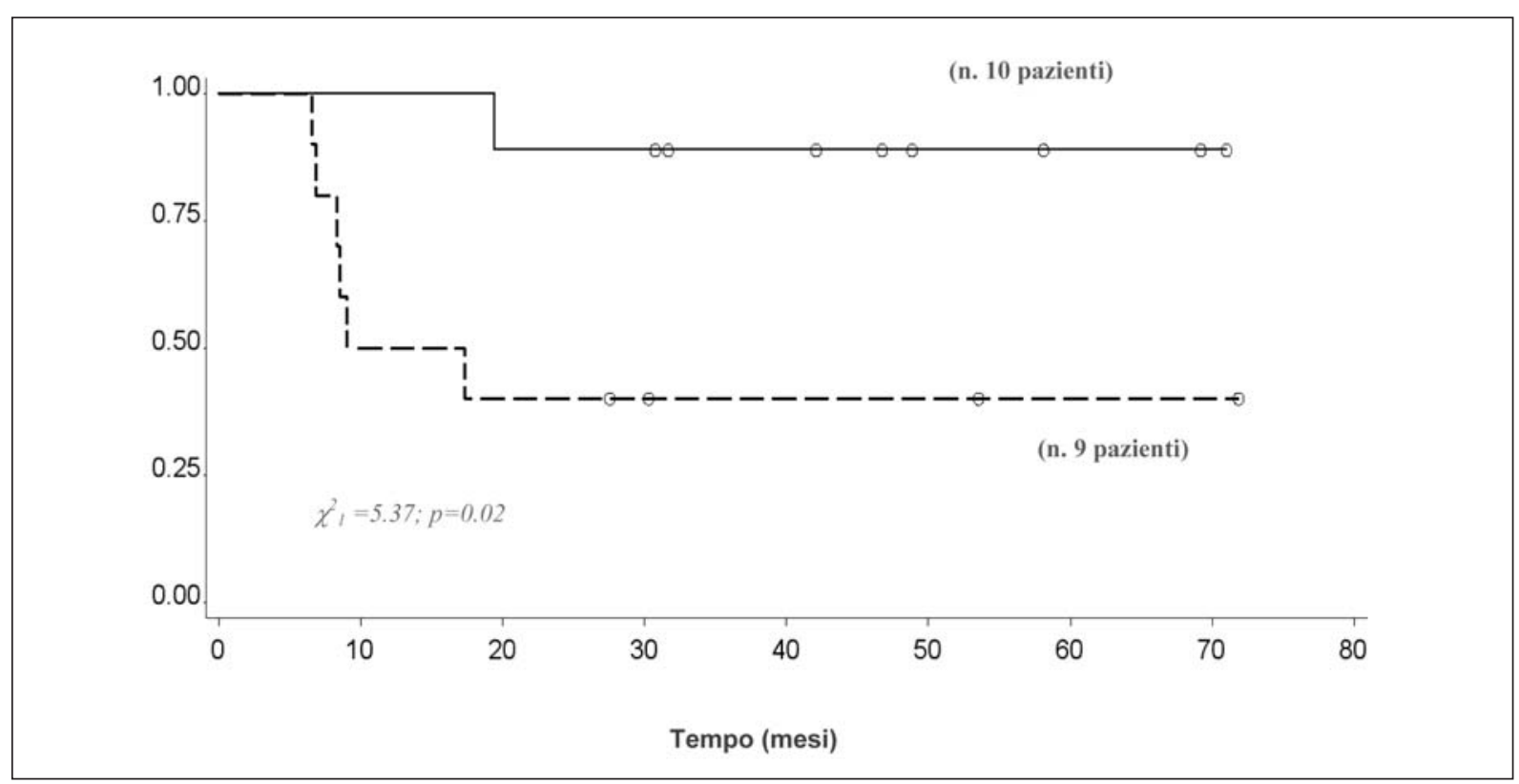

Figura II. Probabilità di sopravvivenza globale per livelli di HIV DNA (__ $\leq$ I/3 contro _ _ > I/3). 


\section{BIBLIOGRAFIA}

1. Avettand-Fenoel V, Boufassa F, Galimand J, et al.. HIV-1 DNA for the measurement of the HIV reservoir is predictive of disease progression in seroconverters whatever the mode of result expression is. J Clin Virol 2008; 42: 399-404.

2. Benicchi T, Ghidini C, Re A, et al. T-cell immune reconstitution after hematopoietic stem cell transplantation for HIV-associated lymphoma. Transplantation 2005; 80: 673-82.

3. Bortolin MT, Pratesi C, Dolcetti R, et al. Clinical value of Epstein-Barr virus DNA levels in peripheral blood samples of Italian patients with undifferentiated carcinoma of nasopharyngeal type. Cancer Lett 2006; 233: 247-54

4. Bortolin MT, Simonelli C, Zanussi S, et al. Effects on virological and immunological parameters during CD34 mobilization in HIV patients with lymphoma. Am J Hematol 2006; 81: 800-2.

5. Bortolin MT, Zanussi S, Pratesi C, et al. HIV-1 DNA in pazienti HIV+ con linfoma riceventi trapianto autologo di cellule staminali (ASCT). Comunicazione orale al XXXVII Congresso Nazionale AMCLI, Stresa, 58 ottobre 2008.

6. Chun TW, Engel D, Berrey MM, et al. Early establishment of a pool of latently infected, resting CD4(+) T cells during primary HIV-1 infection. Proc Natl Acad Sci USA 1998; 95: 8869-73.

7. Dalmasso C, Carpentier W, Meyer L, et al. Distinct genetic loci control plasma HIV-RNA and cellular HIV-DNA levels in HIV-1 infection: the ANRS Genome Wide Association 01 study. PLoS ONE 2008; 3: e3907.

8. Douek DC, Brenchley JM, Betts MR, et al. HIV preferentially infects HIVspecific CD4+ T cells. Nature 2002; 417: 95-8.

9. Finzi D, Hermankova M, Pierson T, et al. Identification of a reservoir for HIV-1 in patients on highly active antiretroviral therapy. Science 1997; 278: $1295-300$.

10. Gabarre J, Marcelin AG, Azar N, et al. High-dose therapy plus autologous hematopoietic stem cell transplantation for human immunodeficiency virus (HIV)-related lymphoma: results and impact on HIV disease.
Haematologica 2004; 89: 1100-8.

11. Koelsch KK, Liu L, May S, et al.. Dynamics of total, linear non-integrated, and integrated HIV-1 DNA in vivo and in vitro. J Inf Dis 2008; 197: 411-19.

12. Kostrikis LG, Touloumi G, Karanicolas R, et al. Quantitation of human immunodeficiency virus type 1 DNA forms with the second template switch in peripheral blood cells predicts disease progression independently of plasma RNA load. J Virol 2002; 76: 10099-108.

13. Krishnan A, Molina A, Zaia J, et al. Durable remissions with autologous stem cell transplantation for high-risk HIV-associated lymphomas. Blood 2005; 105: 874-8.

14. Re A, Cattaneo C, Michieli M, et al. High-dose therapy and autologous peripheral-blood stem-cell transplantation as salvage treatment for HIVassociated lymphoma in patients receiving highly active antiretroviral therapy. J Clin Oncol 2003; 21: 4423-7.

15. Resino S, Pérez A, Seoane E, et al. Immune reconstitution after autologous peripheral blood stem cell transplantation in HIV-infected patients: might be better than expected? AIDS Res Hum Retroviruses 2007; 23: 543-8.

16. Rouzioux C, Hubert JB, Burgard M, et al. Early levels of HIV-1 DNA in peripheral blood mononuclear cells are predictive of disease progression independently of HIV-1 RNA levels and CD4+ T cell counts. J Infect Dis 2005; 192: 46-55.

17. Sarmati L, Parisi SG Nicastri E, et al. Cellular HIV-1 DNA quantitation in patients during simplification therapy with protease inhibitor-sparing regimens. J Med Virol 2007; 79: 880-6.

18. Serrano D, Carrión R, Balsalobre P, et al. HIV-associated lymphoma successfully treated with peripheral blood stem cell transplantation. Exp Hematol 2005; 33: 487-94.

19. Tierney C, Lathey JL, Christopherson C, et al. Prognostic value of baseline human immunodeficiency virus type 1 DNA measurement for disease progression in patients receiving nucleoside therapy. J Infect Dis 2003; 187: $144-8$.

20. Viard JP, Burgard M, Hubert JB, et al. Impact of 5 years of maximally successful highly active antiretroviral therapy on CD4 cell count and HIV-1 DNA level. AIDS 2004; 18: 45-9. 